\title{
Demonstration of antibodies to collagen and of collagen-anticollagen immune complexes in rheumatoid arthritis synovial fluids
}

J. MENZEL, C. STEFFEN, G. KOLARZ, R. EBERL, O. FRANK, AND N. THUMB From Institut für Immunologie and II. Medizinische Klinik, Universität Wien, Vienna; II. Medizinische Abteilung, Krankenhaus Lainz, Vienna; and Sonderheilanstalt für Rheumakranke, Baden, Austria

\begin{abstract}
Menzel, J., Steffen, C., Kolarz, G., Eberl, R., Frank, O., and Thumb, N. (1976). Annals of the Rheumatic Diseases, 35, 446-450. Demonstration of antibodies to collagen and of collagen-anticollagen immune complexes in rheumatoid arthritis synovial fluids. Twenty-nine synovial fluids from patients with rheumatoid arthritis (RA) and 10 synovial fluids from patients with other joint diseases were investigated with regard to the presence of antibodies to denatured human collagen and of collagen-anticollagen immune complexes. 12 of the 29 RA synovial fluids showed anticollagen titres from 1: 16 to $1: 512$ in passive haemagglutination. Only one patient in the group with no arthritis had a significant anticollagen titre of $1: 32$. Digestion of the synovial fluids with bacterial collagenase resulted in an anticollagen titre increase from two to four dilution steps in 9 of the RA fluids, while 6 previously negative RA synovial fluids showed anticollagen titres from $1: 32$ to $1: 128$ after digestion with collagenase. These results indicate the existence of collagen-anticollagen immune complexes in 15 of the 29 RA synovial fluids investigated.
\end{abstract}

Several lines of evidence indicate that chronic inflammation in rheumatoid arthritis (RA) may be induced by immune mechanisms, among which the liberation and persistence of antigen in the intraarticular space could be of considerable importance. After induction of local antibody production in the synovial tissue the antigen may engage in the formation of antigen-antibody complexes. The nature of the antigen(s) involved is still uncertain. One of the major components of joint tissue is collagen.

Using the antiglobulin consumption test and bovine collagen as antigen, Steffen and others (1968) showed collagen antibodies in $39.8 \%$ of $276 \mathrm{RA}$ sera. In classifying these cases according to the severity of disease, $88 \%$ of cases with a severe and rapidly progressive form of RA had collagen antibodies, while only $29.2 \%$ of patients with a mild or less severe course of disease had these antibodies. In 99 control cases only 10 sera showed collagen antibodies. Using human collagen as antigen, Steffen and others (1973) obtained simila results with $238 \mathrm{RA}$ sera and 50 control sera. Michaeli and Fudenberg (1974) confirmed these findings with the haemagglutination technique in showing anticollagen antibodies in about $60 \%$ of 100 arthritis sera and about $9 \%$ of 400 age- and sex-matched control sera. Steffen and others (197\%, using the antiglobulin consumption test, showed anticollagen antibodies in RA synovial fluids and proved the autoantibody property of these an bodies. In a recent study, Cracchiolo and others (1975) also showed antibodies to denatured ange native collagen in RA synovial fluids. With doublestaining immunofluorescence, Steffen, Ludwig, an Knapp (1974) observed that collagen and IgG wefee located in identical positions in inclusions of $R \bar{A}$ synovial fluids, indicating the presence of collage? anticollagen complexes.

The demonstration of immune complexes by enzymatic cleavage of the antigen was introduced iby Harbeck and others (1973). Menzel (197\%) 
identified in an in vitro system the presence of collagen-anticollagen complexes by collagenasedigestion. This paper describes investigations on the collagenase-digestion of synovial fluids from patients with RA or other joint diseases.

\section{Materials and methods}

\section{PATIENTS}

Synovial fluids from 29 patients with classical or definite RA, 5 patients with osteoarthrosis, 2 with psoriatic arthritis, and 3 with chronic effusions secondary to traumatic lesions of the knee joint were investigated.

\section{SYNOVIAL FLUID PREPARATION}

Synovial fluids were obtained by knee-joint puncture and were centrifuged at $10000 \mathrm{~g}$ for 15 minutes at $4^{\circ} \mathrm{C}$. The supernatants were dialysed for 20 hours against a large excess of phosphate-buffered saline (PBS) containing $0.02 \%$ sodium azide and $0.005 \mathrm{~mol} / 1$ calcium acetate. To $1 \mathrm{ml}$ of the dialysed fluids $50 \mathrm{NF}$ units of bovine testicular hyaluronidase, $\mathrm{B}$ grade (Calbiochem, Lucerne, Switzerland), were added. The synovial fluids were then incubated with gentle shaking for 1 hour at $37^{\circ} \mathrm{C}$. Aliquots of these fluids were used for serological investigation before or after collagenase treatment.

\section{COLLAGENASE-DIGESTION OF SYNOVIAL FLUIDS}

\section{Method A (collagenase in solution)}

Synovial fluid preparations were incubated with $0 \cdot 2$ $\mathrm{mg} / \mathrm{ml}$ bacterial collagenase (clostridiopeptidase A, EC 3.4.4.19), A grade (Calbiochem, Lucerne), at $37^{\circ} \mathrm{C}$ for 1 hour. Collagen debris was eliminated by dialysis for 20 hours at $4^{\circ} \mathrm{C}$ against a large excess of PBS containing $0.02 \%$ sodium azide and $0.01 \mathrm{~mol} / 1$ EDTA. During this part of the dialysis some of the glycosaminoglycans which were split by hyaluronidase were also eliminated.

\section{Method B (carrier-bound collagenase)}

BrCN-Sepharose (Pharmacia, Uppsala, Sweden) was reacted with bacterial collagenase (clostridiopeptidase $\mathrm{A}$, EC 3.4.4.19), B grade (Calbiochem, Lucerne), at $\mathrm{pH}$ 9.0. The collagenase-conjugate obtained from $1 \mathrm{~g}$ BrCH-Sepharose contained $2 \mathrm{mg}$ of coupled collagenase equivalent to 40 units. The conjugate was suspended in PBS and transferred to a glass column $(1 \times 10 \mathrm{~cm})$. One $\mathrm{ml}$ synovial fluid was applied to the column and was pumped at room temperature through the gel at a constant velocity of $20 \mathrm{ml} / \mathrm{h}$. Buffer was added to ensure complete elution. The eluate was monitored with a Hitachi Photometer Model 101, adapted with a flow cell, at $280 \mathrm{~nm}$. The proteincontaining eluate was concentrated by a Minicon B 15 unit (Amicon Corp., Lexington, Ky.) to a volume of $1 \mathrm{ml}$. The dilution of the sample effected by its passage through the column amounted to approximately $1: 10$. The synovial fluids were then dialysed against a large excess of PBS containing $0.02 \%$ sodium azide $(20 \mathrm{~h}$ at $\left.4^{\circ} \mathrm{C}\right)$.
PREPARATION AND CHEMICAL ANALYSIS OF ACID SOLUBLE COLLAGEN

Acid soluble collagen (ASC) was prepared from human baby dura mater according to Steffen and Timpl (1962). The purity of the preparation, as ascertained by hydroxyproline determination according to Stegemann (1958), was $96 \%$. Amino acid analysis was consistent with it being essentially type I collagen. For serological investigations and in vitro preparation of collagenanticollagen complexes the lyophilized ASC was dissolved in $0.1 \%$ acetic acid to a concentration of 100 $\mathrm{mg} / 100 \mathrm{ml}$. In order to obtain denatured acid soluble collagen (DASC), this solution was heated for $\mathbf{3 0}$ minutes at $40^{\circ} \mathrm{C}$.

PASSIVE HAEMAGGLUTINATION AND HAEMAG GLUTINATION - IN H I BITION

Haemagglutination was performed according to Steffen, Timpl, and Wolff (1964). In the treatment of synovial fluids with collagenase in solution samples were serially diluted after enzymatic treatment with PBS containing $0.01 \mathrm{~mol} / 1$ EDTA to inhibit collagenase activity. If carrier-bound collagenase was used, dilutions were performed with PBS.

COLlagenase-treatment OF IN VITRO PREPARED IMMUNE COMPLEXES

Rabbits were immunized with DASC as described by Steffen and Timpl (1962). An antiserum with an anticollagen titre of 1:2048 was used for the preparation of collagen-anticollagen complexes. In haemagglutinationinhibition the concentration of DASC necessary to completely inhibit the antiserum was determined. A series of antiserum/antigen-mixtures containing increasing amounts of DASC up to the twofold concentration necessary for complete inhibition was incubated for 30 minutes at $37^{\circ} \mathrm{C}$. Aliquots of these immune complex preparations were tested in passive haemagglutination before and after collagenase digestion.

\section{LATEX-TEST FOR RHEUMATOID FACTOR}

Antiglobulin activity of synovial fluids was determined with latex particles coated with aggregated human IgG (Behringwerke, W. Germany).

Table I Effect of treatment with collagenase on anticollagen serum and on in vitro prepared collagenanticollagen complexes

\begin{tabular}{lll}
\hline $\begin{array}{l}\text { Collagen inhibitor * } \\
(\mathrm{mg} / \mathrm{l00ml})\end{array}$ & $\begin{array}{l}\text { Anticollagen titre after addition of } \\
\text { inhibitor to antiserum }\end{array}$ \\
\cline { 2 - 3 } & $\begin{array}{l}\text { Before collagenase } \\
\text { digestion }\end{array}$ & $\begin{array}{l}\text { After collagenase } \\
\text { digestion } \dagger\end{array}$ \\
\cline { 2 - 2 } & $1: 2048$ & $1: 2048$ \\
$\overline{2}$ & $1: 16$ & $1: 2048$ \\
4 & $1: 4$ & $1: 2048$ \\
8 & - & $1: 2048$ \\
16 & - & $1: 2048$ \\
16 & - & $1: 2048$ \\
\hline
\end{tabular}

* Denatured acid soluble collagen (DASC).

+ Method A and Method B. 
Table II Anticollagen-antibody titre in RA synovial fluids before and after digestion with collagenase

\begin{tabular}{|c|c|c|c|c|}
\hline \multirow[t]{2}{*}{ Case no. } & \multirow[t]{2}{*}{$\begin{array}{l}\text { Reciprocal titre before collagenase } \\
\text { digestion }\end{array}$} & \multicolumn{2}{|c|}{$\begin{array}{l}\text { Reciprocal titre after collagenase } \\
\text { digestion }\end{array}$} & \multirow[t]{2}{*}{$\begin{array}{l}\text { Reciprocal titre of latex } \\
\text { agglutination }\end{array}$} \\
\hline & & Method A & Method B & \\
\hline 1 & - & - & - & 80 \\
\hline 2 & - & - & - & 160 \\
\hline$\overline{3}$ & - & - & - & 160 \\
\hline 4 & - & - & - & 320 \\
\hline 5 & - & - & - & 320 \\
\hline 6 & 32 & 32 & 32 & 160 \\
\hline 7 & 128 & 128 & 128 & 40 \\
\hline 8 & 256 & 256 & 256 & 40 \\
\hline 9 & 64 & 64 & 128 & 40 \\
\hline 10 & 128 & 256 & 128 & - \\
\hline 11 & 2 & 4 & 4 & 20 \\
\hline 12 & 16 & 32 & 32 & 20 \\
\hline 13 & 128 & 256 & 256 & 40 \\
\hline 14 & 8 & 32 & 32 & 20 \\
\hline 15 & 8 & 32 & 32 & - \\
\hline 16 & 512 & 2048 & 2048 & 80 \\
\hline 17 & 32 & 256 & 128 & - \\
\hline 18 & 32 & 128 & 128 & 160 \\
\hline 19 & 16 & 128 & 256 & 80 \\
\hline 20 & 32 & 512 & 256 & 160 \\
\hline 21 & - & 8 & 8 & 40 \\
\hline 22 & 2 & 32 & 64 & 160 \\
\hline 23 & 2 & 32 & 16 & 20 \\
\hline 24 & - & 32 & 32 & - \\
\hline 25 & - & 32 & 64 & - \\
\hline 26 & - & 64 & 64 & 320 \\
\hline $\begin{array}{l}27 \\
28\end{array}$ & - & $\begin{array}{r}64 \\
128\end{array}$ & $\begin{array}{r}128 \\
64\end{array}$ & $4 \overline{0}$ \\
\hline 29 & - & 128 & 128 & 40 \\
\hline
\end{tabular}

\section{Results}

Preliminary experiments showed that an anticollagen antiserum of titre $1: 2048$ could be completely inhibited by the addition of DASC to a concentration of $8 \mathrm{mg} / 100 \mathrm{ml}$. According to this result aliquots of the antiserum were incubated with increasing amounts of DASC and subjected to collagenase digestion. Anticollagen titres were determined before and after collagenase treatment. Table I shows partial or complete inhibition after addition of inhibitor and complete reappearance of original anticollagen titre after collagenase digestion.

To compare the experiments performed in vitro, a total of 39 synovial fluids were investigated before and after collagenase digestion for the presence of anticollagen antibodies. Table II gives results obtained in 29 synovial fluids from RA patients. Latex titres are also given.

Table III summarizes these results with regard to the existence of collagen-anticollagen complexes in the RA synovial fluids. Anticollagen titres up to 1: 8 were defined as dubiously positive, titres $1: 16$ and above as distinctly positive. A titre increase after collagenase digestion of at least two dilution steps was accepted as evidence for the presence of collagen-anticollagen complexes. We found tha尺 15 of 29 RA synovial fluids contained collagen $\vec{\delta}$ anticollagen complexes. Of the remaining 14 fiuids 7 had free anticollagen antibodies. Therefore, total of 22 synovial fluids contained free or complex bound anticollagen antibodies.

Table III Effect of collagenase-digestion on haemag glutination results obtained with $R A$ synovial fluids

Evaluation of anticollagen titre after collagenase digestion

No change or insignificant titre increase Negative: no free antibodies, no complexes

Dubiously positive $(1: 2-1: 8)$ : dubious free antibodies, no complexes

Positive $(>1: 8)$ : free antibodies, no complexes

Case no.

Significant titre increase $(\geqslant+2$ steps)

Negative to positive $(>1: 8)$ : complexes

Dubiously positive to positive: dubious free antibodies, complexes

Positive to stronger positive: free antibodies and complexes 
Table IV Anticollagen-antibody titre in non-RA synovial fluids before and after digestion with collagenase

\begin{tabular}{|c|c|c|c|c|}
\hline \multirow[t]{2}{*}{ Case no. } & \multirow[t]{2}{*}{ Diagnosis } & \multirow[t]{2}{*}{$\begin{array}{l}\text { Reciprocal titre before } \\
\text { collagenase digestion }\end{array}$} & \multicolumn{2}{|c|}{$\begin{array}{l}\text { Reciprocal titre after } \\
\text { collagenase digestion }\end{array}$} \\
\hline & & & Method A & Method B \\
\hline $\begin{array}{l}30 \\
31 \\
32\end{array}$ & $\begin{array}{c}\text { Arthrosis } \\
\quad,\end{array}$ & $\overline{4}$ & $\begin{array}{l}8 \\
4\end{array}$ & $\begin{array}{r}16 \\
4\end{array}$ \\
\hline 33 & ", & $3 \overline{2}$ & $6 \overline{4}$ & $3 \overline{2}$ \\
\hline 34 & & - & - & - \\
\hline 35 & Trauma & $\overline{0}$ & - & $\overline{0}$ \\
\hline 36 & " & 2 & 2 & 2 \\
\hline 37 & D"rintis merthriti & - & - & - \\
\hline $\begin{array}{l}38 \\
39\end{array}$ & Psoriatic arthritis & 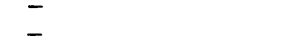 & - & - \\
\hline & $"$ & - & - & - \\
\hline
\end{tabular}

Table IV gives the results obtained with synovial fluids from control patients. Defining again titres higher than $1: 8$ as distinctly positive, only one of 10 synovial fluids showed the presence of anticollagen antibodies.

\section{Discussion}

Investigations by different groups (Steffen and others, 1968; Kriegel and others, 1970; Michaeli and Fudenberg, 1974; Steffen and others, 1973; Frank, 1974) showed that 40 to $50 \%$ of sera from RA patients contain antibodies to denatured collagen, while only about $10 \%$ of healthy individuals were found to have these antibodies. In addition to the markedly higher incidence of anticollagen antibodies, patients with RA have significantly higher anticollagen titres than control patients. Anticollagen titres in RA patients are furthermore found to increase with the severity of disease (Steffen and others, 1968; Frank, 1974). Anticollagen antibodies were also shown in RA synovial fluids (Steffen and others, 1971; Cracchiolo and others, 1975).

Further studies in this field showed that collagenanticollagen complexes prepared in vitro are ingested by phagocytosing cells (Steffen and others, 1974), that collagen as well as collagen-anticollagen complexes can be observed as inclusions in RA synovial fluid cells (Steffen and others, 1972), and that collagen-anticollagen complexes prepared in vitro possess inflammatory activity as shown in passive cutaneous anaphylaxis (Menzel and Steffen, 1975). Injection of collagen into the knee joints of collagen-immunized rabbits induced experimental arthritis (Steffen and others, 1975). These findings indicate a possible pathogenetic role of collagenanticollagen immune complexes in RA (Steffen, 1970). To obtain further evidence on the involvement of anticollagen antibodies and collagenanticollagen complexes in RA, synovial fluids of RA patients and controls were investigated with regard to the presence of such immune complexes. This study was restricted to synovial fluids since earlier investigations had shown that a correlation exists between the presence of anticollagen antibodies in sera and synovial fluids (Cracchiolo and others, 1975).

To determine the proportions of free and complex-bound anticollagen antibodies, collagenase digestion was used. Similar experiments were performed by Harbeck and others (1973), who used DNAse to show DNA-anti-DNA immune complexes. In preliminary in vitro experiments we showed that collagen can be digested by collagenase of bacterial origin even after forming complexes with anticollagen antibodies. The enzymatic digestion of the antigen causes the disruption of the immune complexes and the liberation of reactive antibodies. In further studies Menzel (1976) showed that collagen-anticollagen complexes prepared in vitro, which were isolated by gel filtration, can also be disrupted by using identical methods of collagenase digestion as described in this study.

Our results show that 22 of the 29 RA synovial fluids investigated contained anticollagen antibodies with titres up to $1: 512$. In 15 of these antibodypositive fluids part or all of the antibodies were present as immune complexes ('hidden' antibodies). These results are based on defining an antibody titre higher than 1:8 as distinctly positive and on considering an increase in titre after collagenase digestion of at least two steps as significant for the demonstration of immune complexes. Anticollagen antibody titre or the amount of collagen-anticollagen complexes appeared to be unrelated to the presence of rheumatoid factors. This finding corresponds to the results obtained by Cracchiolo and others (1975).

In the non-RA group of 10 patients, 2 had nonsignificant anticollagen titres of $1: 2$ and $1: 4$, while only one showed a titre of $1: 32$, which was, however, not altered by collagenase digestion.

To avoid any artefactual effects on haemag- 
glutination due to differences in the viscosity of synovial fluids, all fluids were digested with hyaluronidase. Cracchiolo and others (1975) used for the same reason caesium chloride density gradient ultracentrifugation to separate hyaluronate protein from immunoglobulins. The use of hyaluronidase, which degrades glycosaminoglycans such as hyaluronate and chondroitin sulphate, has an additional advantage. It is possible that interaction between collagen-coated erythrocytes and glycosaminoglycans present in the synovial fluids simulates an antigen-antibody reaction in passive haemagglutination by aggregating the red blood cells nonspecifically (Conochie, Scott, and Faulk, 1975). However, as the synovial fluids investigated by us were digested with hyaluronidase, a large part of the glycosaminoglycans could be eliminated by dialysis. We observed furthermore that no agglutination of human erythrocytes coated with denatured collagen was caused by incubation of these cells with chondroitin-4-sulphate or chondroitin-6-sulphate up to a concentration of $1 \mathrm{mg} / \mathrm{ml}$.

Our findings suggest that anticollagen antibodies and/or immune complexes of collagen exist in RA synovial fluids. The presence of anticollagen antibodies could be due to chronic antigenic stimulation of immunocytes in the synovial tissue induced by products of enzyme-mediated collagen breakdown. Antibodies to collagen may form immune complexes by reacting with collagen debris set free by enzymatic action. The importance of such complexes for the pathogenesis or chronic perpetuation of RA and their possible effect on progressive cartilage destruction remains to be investigated.

Our thanks are due to Dr. W. Hampel, Technical University, Vienna, for the amino acid analyses. The capable technical help of Mrs. Camelia Pick is gratefully acknowledged.

\section{References}

CoNochiE, L. B., ScotT, J. E., AND FAULK, W. P. (1975) J. immunol. Meth., 7, 393 (A passive agglutination method using collagen-coated tanned sheep erythrocytes to demonstrate collagen-glycosaminoglycan interaction)

Craccholo, A., Michaeli, D., Goldberg, L. S., ANd Fudenberg, H. H. (1975) Clin. Immunol. Immunopath., 3, 567 (The occurrence of antibodies to collagen in synovial fluids)

FraNK, O. (1974) Wien. klin. Wschr., 86, Suppl. 30 (Klinische und immunologische Parameter der progredient chronischen Polyarthritis als Grundlage für die Aktivitätsdiagnostik und die Verlaufskontrolle)

HaRbeck, R. J., Hoffman, A. A., CARR, R. I., AND Bardana, E. J. (1973) Arthr. and Rheum., 16, 552 (DNA antibodies and DNA: anti-DNA complexes in cerebrospinal fluid of patients with SLE)

KRIEGel, W., LANGNeSS, U., JAHN, P., AND MÜlleR, W. (1970) $Z$. Rheumaforsch., 29, 173 ('Collagen-like protein' und Kollagenantikörper bei der chronischen Polyarthritis)

MENZEL, J. (1976) Z. Immun.-Forsch. (in press) (Identification of collagen-anticollagen immune complexes by collagenase digestion)

- AND STEFFen, C. (1975) Ibid., 150, 114 (Biologic activity of soluble collagen-anticollagen immune complexes as demonstrated by passive cutaneous anaphylaxis).

Michaeli, D., AND FudENBERG, H. H. (1974) Arthr. and Rheum., 14, 404 (Incidence of antibodies to denatured collagen in rheumatoid arthritis)

StefFEN, C. (1970) Z. Immun.-Forsch., 139, 219 (Consideration of pathogenesis of rheumatoid arthritis as collagen autoimmunity)

- AND TIMPL, R. (1962) Z. Rheumaforsch., 21, 417 ((Untersuchungen über die Bedeutung von Kollagen in der Rheumaserologie)

,,-- AND WoLFF, I. (1964) J. Immunol., 93, 656 (Immunogenicity and specificity of collagen. II. Investigations about specificity of collagen and its derivatives by passive haemagglutination and haemagglutination-inhibition of anti-collagen and anti-parent gelatine immune sera)

- LUDWIG, H., AND KNAPP, W. (1974) Z. Immun.-Forsch., 147, 229 (Collagen-anticollagen immune complexes in rheumatoid arthritis synovial fluid cells)

-, Schuster, C., Tausch, G., Timpl, R., AND PeCKer, I. (1968) Wien. klin. Wschr., 46, 976 (WeitereUntersuchungen über Kollagenantikörper bei Patienten mit primär chronischer Polyarthritis)

- CARmann, H., Schuster, F., TAusCh, G., Bösch, J., AND Freilinger, G. (1971) Z. Rheumaforsch., 30, 92 (Untersuchungen über die Autoantikörpereigenschaft von Kollagenantikörpern und ihr Vorkommen in der Synovia von Patienten mit rheumatoider Arthritis)

- KNaPP, W., Thumb, N., SChUSTER, F., Bösch, J., BRUnNeR, H., AND EIrL, M. (1972) Z. Immun.-Forsch., 143,252 (Demonstration of collagen in synovial fluid cells of RA patients with immunofluorescence)

- LUDWIG, H., KovAC, W., AND MenZEL, J. (1975) Ibid., 150, 432 (Collagen-induced acute synovitis in collagen-immunized rabbits)

,-- , Thumb, N., Frank, O., EberL, R., AND TAusCh, F. (1973) Wien. klin. Wschr., 51, 222 (Nachweis von Antikörpern mit verschiedener Kollagenspezifität bei progressiv chronischer Polyarthritis und Vergleich von Humankollagen und Kalbskollagen als Testantigen)

StegemanN, H. (1958) Hoppe-Seyler's Z. physiol. Chem., 311, 41 (Mikrobestimmung von Hydroxyprolin mit Chloramin-T und p-Dimethylaminobenzaldehyd) 